\title{
Vigencia de los Derechos Humanos en el marco de los diferentes planes de Emergencia que han aplicado los Estados con motivo del COVID-19
}

Validity of Human Rights within the framework of the different Emergency plans that have been applied by the States on the occasion of COVID-19

\author{
Maria Fatima Pinho de Oliveira ${ }^{1}$ \\ Universidad Simón Bolivar - Venezuela
}

Revista Derechos en Acción ISSN 2525-1678/ e-ISSN 2525-1686

Año 5/Nº 15, Otoño 2020 (21 marzo a 21 junio), 336-364

DOI: https://doi.org/10.24215/25251678e403

\section{A manera de introducción}

En diciembre de 2019 en Wuhan, China, se conoció la noticia de un brote de enfermedad por coronavirus (COVID-19). Para el 11 de marzo de 2020, la Organización Mundial de la Salud (OMS), declaró que había alcanzado el nivel de pandemia mundial y le solicitó a los gobiernos que tomasen medidas urgentes y contundentes para detener la propagación del virus.

Entre tanto, cabe destacar que, las normas del Derecho Internacional de los Derechos Humanos garantiza que todas las personas disfruten del derecho de salud y obliga a los gobiernos a adoptar medidas para prevenir las amenazas a la salud

\footnotetext{
1 Profesora Asociado de la Universidad Simón Bolívar, adscrita al Departamento de Ciencias Económicas y Administrativas en Caracas, Venezuela. Abogado de la Universidad Santa Maria (USM, 1999). Especialista en Derecho Penal (USM, 2001) y Magíster en Derecho Penal (USM, 2008). Doctorando en Derecho Internacional Público de la Universidad Latinoamericana y del Caribe (ULAC). (ORCID 0000-0002-7539-5620).Correo electrónico: mpinho@usb.ve.
} 
pública y brindar atención médica a quienes la necesitan; y bajo esta amenaza de emergencia y salud pública las restricciones a algunos derechos pueden justificarse siempre y cuando cumplan con los siguientes criterios: que tengan una base legal, sean estrictamente necesarias según evidencias científicas y no sean arbitrarias ni discriminatorias en su aplicación, sean de duración limitada, respeten la dignidad humana, estén sujetas a revisión y sean proporcionales para lograr su objetivo.

Efectivamente, la pandemia del COVID-19, asciende al nivel de una amenaza a la salud pública que, para garantizar el derecho a la salud, podría justificar restricciones a ciertos derechos, como los que resultan de la imposición de la cuarentena o el aislamiento y que limitan la libertad de tránsito o movimiento. Así mismo, una esmerada atención a derechos humanos como la no discriminación y principios de los derechos humanos como la transparencia y el respeto a la dignidad humana, puede fomentar una respuesta efectiva en medio de la agitación y los trastornos que inevitablemente resultan en tiempos de crisis, además de limitar los daños que provengan de la imposición de medidas muy generales que no cumplan con los criterios anteriores. (Human Rights Watch, 2020).

Las oficinas de Naciones Unidas, la Comisión Interamericana de Derechos Humanos, la Organización para la Seguridad y la Cooperación en Europa, la Organización Mundial de la Salud, la Organización Panamericana de la Salud y Access Now, ante la pandemia de COVID-19, recomiendan a los gobiernos, que a través de la implementación de planes e intervenciones fundamentadas en el respeto a los derechos humanos y las garantías digitales, deben proteger la vida de los ciudadanos.

Estas instancias han mostrado su preocupación por el control de las libertades en los decretos de emergencia, las medidas de censura, la penalización de las opiniones en internet y la desinformación que se ha esparcido en entornos digitales y comunitarios a la par del nuevo coronavirus; donde la prioridad es la salvaguarda del derecho a la salud, el acceso al servicio de agua, el amparo de los migrantes, el respeto a las libertades 
informativas, la protección de datos personales y los derechos digitales. (Chirinos, 2020).

En estas breves líneas se presenta un análisis de la vigencia de los DDHH en el marco de los diferentes planes de Emergencia que han aplicado los Estados con motivo del COVID-19, mencionando algunos derechos humanos y reflexionando sobre las medidas implementadas por algunos Estados.

\section{Las Normas Internacionales en materia de Derecho Internacional}

De conformidad con lo establecido en el Pacto Internacional de Derechos Económicos, Sociales y Culturales, adoptado por la mayoría de los países, todas las personas tienen derecho al "más alto nivel posible de salud física y mental" y los gobiernos están obligados a tomar medidas efectivas para "la prevención, el tratamiento de las enfermedades epidémicas, endémicas, profesionales y de otra índole, y la lucha contra ellas". (Human Rights Watch, 2020)

El Comité de Derechos Económicos, Sociales y Culturales de las Naciones Unidas (CDESC), que supervisa el cumplimiento del pacto por parte de los Estados, ha declarado que:

El derecho a la salud está estrechamente vinculado con el ejercicio de otros derechos humanos y depende de esos derechos, que se enuncian en la Carta Internacional de Derechos, en particular el derecho a la alimentación, a la vivienda, al trabajo, a la educación, a la dignidad humana, a la vida, a la no discriminación, a la igualdad, a no ser sometido a torturas, a la vida privada, al acceso a la información y a la libertad de asociación, reunión y circulación. Esos y otros derechos y libertades abordan los componentes integrales del derecho a la salud.

El derecho a la salud establece que los establecimientos, bienes y servicios de salud deberían:

- Ser suficientes en cantidad y disponibilidad. 
- Ser accesibles y estar al alcance de todos, sin discriminación alguna, incluso a los sectores más vulnerables y marginados de la población.

- Ser apropiados desde el punto de vista científico y médico, y ser de buena calidad.

Los Principios de Siracusa, adoptados por el Consejo Económico y Social de las Naciones Unidas en 1984, y las observaciones generales del Comité de Derechos Humanos de las Naciones Unidas sobre los estados de emergencia y la libertad de movimiento brindan directrices autorizadas sobre las respuestas gubernamentales que restringen los derechos humanos por razones de salud pública o emergencia nacional. Cualquier medida tomada para proteger a la población que limite los derechos y libertades de las personas debe ser legal, necesaria y proporcional. Los estados de emergencia deben tener una duración limitada y cualquier reducción de los derechos debe tener en cuenta el impacto desproporcionado en poblaciones específicas o grupos marginados. (Human Rights Watch, 2020)

Un grupo de expertos en derechos humanos de la ONU, el 16 de marzo de 2020, manifestaron que: "...las declaraciones de emergencia basadas en el brote de COVID-19 no deberían usarse como excusa para atacar a grupos, minorías o individuos particulares. No deberían utilizarse como una tapadera para acciones represivas con el pretexto de proteger la salud (...) y no deberían usarse simplemente para sofocar la disidencia". (Human Rights Watch, 2020)

Los Principios de Siracusa establecen específicamente que, como mínimo, las restricciones, deben:

- Imponerse y aplicarse de conformidad con la ley.

- Responder a un objetivo legítimo de interés general.

- Ser estrictamente necesarias en una sociedad democrática para alcanzar su objetivo.

- Ser lo menos intrusivas y restrictivas posible para cumplir su objetivo. 
- Basarse en evidencia científica y no aplicarse de manera arbitraria ni discriminatoria.

- Tener una duración limitada, ser respetuosas con la dignidad humana y estar sujetas a revisión. (Human Rights Watch, 2020)

\section{Algunos aspectos sobre los Derechos Humanos y el COVID-19}

La Alta Comisionada de las Naciones Unidas para los Derechos Humanos, Michele Bachelet, declaró durante el Consejo celebrado en Ginebra, que “...los confinamientos, las cuarentenas y otras medidas de esa índole orientadas a combatir la expansión del COVID-19 deben aplicarse siempre en la más estricta observación de las normas de derechos humanos y de manera proporcional". El nuevo coronavirus "pone a prueba a nuestras sociedades y todos aprendemos y nos adaptamos a medida que respondemos al virus. Pero es preciso que la dignidad y los derechos humanos sean los pilares fundamentales de ese esfuerzo y no una consideración accesoria”. (Chirinos, 2020).

A continuación se presentan un breve análisis en torno a algunos Derechos Humanos afectados por las medidas implementadas por el COVIT-19.

\section{Derecho a la Libertad}

Cabe destacar que las cuarentenas, en particular las que afectan al derecho a la libertad y la seguridad personales, sólo son permisibles si se llevan a cabo de manera no discriminatoria y, aunque respondan, como este caso, a una necesidad pública o social apremiante, si tienen una finalidad legítima y son proporcionales a ella; deben ser de duración limitada y revisarse periódicamente, y si hay varios tipos de limitaciones posibles, debe adoptarse la menos restrictiva. (Amnistía Internacional, 2020) 
Lo mismo sucede con las restricciones y prohibiciones de viaje, que también pueden afectar al derecho a la libertad de circulación. Cuando se impongan deben ser legítimas, necesarias y proporcionales, es decir, ser la menos restrictiva de las alternativas posibles, y no deben tener carácter discriminatorio. (Amnistía Internacional, 2020). Las medidas tomadas fueron el cierre de las fronteras y la prohibición de los vuelos nacionales e internacionales en varios países.

\section{Derecho a la salud}

De acuerdo a recomendaciones de Amnistía Internacional (2020), los Estados deben garantizar que todas las personas y comunidades afectadas tienen acceso a una información clara, accesible, oportuna y significativa sobre la naturaleza y el grado de amenaza para la salud, a la información sobre las posibles medidas que se tomen para mitigar los riesgos, y también a la información de alerta temprana sobre las posibles consecuencias futuras y las iniciativas de respuesta en curso. Sobre este punto del Derecho al acceso a la información será tratado más adelante.

Los Estados deben garantizar que todas las personas tengan acceso a la seguridad social, incluido el reposo por enfermedad, la atención a la salud y la licencia por maternidad, si están enfermas o en cuarentena o tienen que cuidar de personas dependientes afectadas, incluido niños y niñas debido al cierre de colegios.

Los estándares internacionales sobre el derecho a la salud indican que los bienes, las instalaciones y los servicios de atención médica, incluido el acceso a la atención y las vacunas y curas desarrolladas para COVID-19, deben estar disponibles en cantidad suficiente para todas las personas, especialmente para los sectores más vulnerables o marginados de la población, que deben tener acceso a ellos sin discriminación.

Ese acceso debe ser asequible para todas las personas. Esto significa que los Estados deberían trabajar con las partes implicadas (incluidas las compañías farmacéuticas) para conseguirlo, de 
manera que todos los actores mantengan como prioridad la garantía de los derechos humanos. El derecho a la salud incluye tanto la salud física como la mental. Los Estados deben garantizar que el apoyo psicosocial esté disponible para posibles consecuencias de la epidemia de COVID-19 sobre salud mental y las medidas de contención posteriores, como la ansiedad o la depresión.

Algunas de las medidas aplicadas para mejorar la salud pública pueden tener consecuencias negativas en el derecho al trabajo y los derechos laborales, haciendo que las personas con trabajos precarios se vean afectadas de manera desproporcionada. Entre ellas figuran los trabajadores y trabajadoras migrantes, las personas sujetas a condiciones poco seguras o precarias de trabajo propias de la economía bajo demanda, las personas con bajos ingresos, las personas migrantes en situación administrativa irregular y las personas empleadas en el sector informal. Los Estados deben garantizar que todas ellas también tienen acceso a las prestaciones que ofrece la seguridad social.

Otros grupos de riesgo que deben ser tomados en cuenta son los trabajadores de la salud, los guardias y otros empleados de prisiones u otro personal encargado de hacer cumplir la ley que se ocupe de aplicar y hacer cumplir las medidas de salud pública, así como profesionales que no pertenecen al sector público que están trabajando para garantizar el acceso a servicios básicos, donde los Estados deben garantizar también que se establecen mecanismos en pro de su derecho a la salud como consecuencia de su exposición a COVID-19.

Entre los grupos vulnerables se tienen, las personas de edad y con dolencias médicas preexistentes (como asma, diabetes o cardiopatías) parecen estar más expuestas a enfermar de gravedad por el virus y por lo tanto los Estados deben hacer lo posible por protegerlas. También Personas que viven en la pobreza y con menor acceso a medidas preventivas, incluidas mascarillas y desinfectantes; personas sin hogar que se enfrentan a desafíos importantes para el autoaislamiento; personas migrantes en situación administrativa irregular; personas con ingresos más bajos y empleo inseguro; aquellas que no tienen más remedio 
que vivir o trabajar cerca de otras que no tienen acceso a medidas preventivas adecuadas, como en las cárceles o en entornos laborales que presentan riesgos para la salud; o personas sin acceso adecuado a agua y saneamiento. Los Estados deben velar que puedan acceder a los mismos servicios que el resto de la población sin discriminación.

Bachelet considera que para “...combatir eficazmente la epidemia, es preciso velar por que todos tengan acceso al tratamiento y que no se niegue a nadie la atención sanitaria por motivos económicos o a causa de la estigmatización”. Indicó además que los gobiernos deben dar "especial importancia a la protección de la salud de los propios trabajadores sanitarios”. (Chirinos, 2020)

La CIDH también recomienda que los Estados garanticen el derecho a la salud "...a fin de que prevalezca el debido y oportuno cuidado a la población”. El organismo aconseja establecer planes para atender la salud mental. Para ello es importante implementar "medidas especiales para la protección y entrenamiento del personal sanitario". (Chirinos, 2020)

\section{Derechos de los migrantes y personas marginadas}

La Red de las Naciones Unidas sobre Migración sugiere a los Estados proteger a los migrantes, por lo tanto las restricciones de movilidad durante las cuarentenas y las restricciones de desplazamientos no deben afectar "indebidamente" los derechos humanos de los migrantes y la posibilidad que tiene de "solicitar asilo". "Las medidas deben incluir prevención, pruebas y tratamiento adecuados, acceso continuo y aumentado a refugios de emergencia para personas sin hogar sin barreras relacionadas con el estado migratorio; y suspensiones de desalojos". Los expertos insisten en que "es particularmente importante que las autoridades hagan todo lo posible para enfrentar la xenofobia, incluso cuando los migrantes y otras personas están sujetas a discriminación o violencia relacionada con el origen y la propagación de la pandemia”. (Chirinos, 2020) 
Los gobiernos deberían garantizar que se proporcionen todos los servicios de salud relacionados con el COVID-19, acceder a las pruebas, la atención medica preventiva y el tratamiento, sin estigma ni discriminación de ningún tipo, incluso por motivos de orientación sexual e identidad de género, (LGBT), este grupo en particular enfrentan discriminación para acceder a la atención médica, según informes de casos documentados por Human Rights Watch en países como EE.UU., Tanzania, Japón, Indonesia, Bangladesh, Rusia y el Líbano. En el caso de los inmigrantes indocumentados, los gobiernos deben tomar medidas para asegurar a las poblaciones vulnerables que no corren riesgo de represalias ni de ser deportados si acceden a cuidados vitales.

Todos los gobiernos tienen la obligación de garantizar que una grave crisis de salud pública no se convierta también en una crisis de derechos humanos porque las personas no puedan acceder a una atención médica adecuada. Por lo tanto los gobiernos deberían tomar medidas para garantizar que todas las personas tengan opciones de tratamiento y atención médica asequible y accesible.

La directora para las Américas de Amnistía Internacional, Erika Guevara Rosas, señaló que: "La condición migratoria es irrelevante para la dignidad y el derecho a vivir de todos los seres humanos. En lugar de incrementar los riesgos para la salud de la población, los gobiernos deberían hacer todo lo que puedan para protegerla". Indicó además que: "Para combatir con eficacia el coronavirus, COVID-19, en las Américas e impedir miles de muertes evitables, los Estados deben liberar rápidamente a las personas en detención migratoria, (...) y garantizar que tengan acceso, sin discriminación, a atención médica para salvar sus vidas." (Amnistía Internacional, 2020).

Las autoridades de varios países del continente americano, entre ellos, Canadá, Estados Unidos, México, Curazao y Trinidad y Tobago detienen de forma peligrosa y discriminatoria a migrantes y solicitantes de asilo, basándose únicamente en 
la situación migratoria de esas personas, afirmó hoy Amnistía Internacional. Al hacerlo, empujan a muchas personas a entornos inseguros y poco higiénicos, contrario a las pautas internacionales de derechos humanos y salud pública. (Amnistía Internacional, 2020).

\section{Tabla $\mathbf{N}^{\circ}$ 1. Comparativa de países con ejemplos de casos sobre situaciones de DDHH en relación a Derechos de los migrantes}

\begin{tabular}{|c|c|c|}
\hline Países & Situaciones & $\begin{array}{l}\text { Recomendaciones } \\
\text { de Amnistía } \\
\text { Internacional }\end{array}$ \\
\hline CANADÁ & $\begin{array}{l}\text { La Agencia de Servicios Fronterizos de } \\
\text { Canadá tiene en sus centros de detención } \\
\text { migratoria a algunos cientos de personas } \\
\text { con altas tasas de mortalidad. } \\
\text { Las personas detenidas y sus familias } \\
\text { afrontan un estrés psicológico sustancial, } \\
\text { han estado sometidas a tanta angustia por } \\
\text { el riesgo de contraer el COVID-19 mientras } \\
\text { están detenidas que han iniciado una } \\
\text { huelga de hambre para pedir ser liberadas. }\end{array}$ & $\begin{array}{l}\text { Amnistía Internacional } \\
\text { recomendó reducir } \\
\text { rápidamente al } \\
\text { mínimo el número de } \\
\text { personas en centros de } \\
\text { detención migratoria }\end{array}$ \\
\hline CURAZAO & $\begin{array}{l}\text { Las autoridades de Curazao detienen } \\
\text { con frecuencia a migrantes y solicitantes } \\
\text { de asilo procedentes de Venezuela, } \\
\text { negándoles el acceso a la protección } \\
\text { internacional. } \\
\text { En marzo de 2020, la Plataforma Regional } \\
\text { de Coordinación Interagencial estimó que } \\
\text { había } 16.500 \text { personas venezolanas en la } \\
\text { isla, pero se desconocía cuántas de ellas } \\
\text { estaban en detención migratoria. } \\
\text { Bajo detención Migratoria se han } \\
\text { evidenciado pésimas condiciones, } \\
\text { hacinamiento, abusos sexuales, falta de } \\
\text { higiene y camas inadecuadas en las zonas } \\
\text { en las que estaban detenidas personas en } \\
\text { situación migratoria irregular. }\end{array}$ & $\begin{array}{l}\text { Curazao debe } \\
\text { liberar a todas las } \\
\text { personas migrantes y } \\
\text { solicitantes de asilo } \\
\text { que se encuentran } \\
\text { detenidas por su } \\
\text { condición migratoria } \\
\text { y otorgarles acceso a } \\
\text { la atención de salud } \\
\text { que requieran y a otros } \\
\text { servicios esenciales. }\end{array}$ \\
\hline
\end{tabular}




\begin{tabular}{|c|c|c|}
\hline Países & Situaciones & $\begin{array}{l}\text { Recomendaciones de } \\
\text { Amnistía Internacional }\end{array}$ \\
\hline MÉXICO & $\begin{array}{l}\text { Tras el cierre de la frontera las } \\
\text { autoridades han fallado en no } \\
\text { considerar alternativas a la detención } \\
\text { para las personas migrantes que } \\
\text { están actualmente detenidas, dada } \\
\text { la imposibilidad de ser liberadas } \\
\text { vía la deportación en autobús a } \\
\text { Centroamérica. } \\
\text { Se ha reportado que algunos centros } \\
\text { de detención migratoria están } \\
\text { superpoblados e incluso mezclan a } \\
\text { niños y adolescentes con poblaciones } \\
\text { adultas debido a la falta de espacio. } \\
\text { En marzo } 2020 \text { se reportaron } \\
\text { protestas en los centros de detención } \\
\text { migratoria. } \\
\text { Las autoridades mexicanas podrían } \\
\text { no respetar su propia legislación } \\
\text { migratoria al permitir un régimen } \\
\text { de detención indefinida, lo } \\
\text { cual incumpliría los estándares } \\
\text { internacionales de derechos humanos. }\end{array}$ & $\begin{array}{l}\text { México debe poner } \\
\text { rápidamente en libertad } \\
\text { a todas las personas } \\
\text { migrantes y solicitantes de } \\
\text { asilo que pueda de las que } \\
\text { actualmente se encuentran } \\
\text { en centros de detención } \\
\text { migratoria; la salud mental } \\
\text { y física de esas personas no } \\
\text { se puede preservar en esos } \\
\text { centros. } \\
\text { Las autoridades mexicanas } \\
\text { no solo deben liberarlas, } \\
\text { sino también brindarles } \\
\text { protección humanitaria de } \\
\text { emergencia para garantizar } \\
\text { que todas ellas tengan } \\
\text { acceso sin discriminación } \\
\text { a servicios esenciales, } \\
\text { cuidados y seguridad, } \\
\text { incluidas una alimentación } \\
\text { y una atención de salud } \\
\text { adecuadas. }\end{array}$ \\
\hline $\begin{array}{l}\text { TRINIDAD } \\
\text { Y TOBAGO }\end{array}$ & $\begin{array}{l}\text { No cuenta con una legislación nacional } \\
\text { sobre personas refugiadas. El país } \\
\text { sigue criminalizando y deteniendo } \\
\text { a personas migrantes y refugiadas } \\
\text { (especialmente aquellas que huyen de } \\
\text { la crisis en Venezuela) que ingresan } \\
\text { en su territorio de manera irregular. } \\
\text { Eso es contrario a los estándares } \\
\text { internacionales de derechos humanos. } \\
\text { Amnistía Internacional no ha podido } \\
\text { visitar el Centro de Detención } \\
\text { Migratoria. Tampoco se les otorga } \\
\text { acceso a otras organizaciones no } \\
\text { gubernamentales y de derechos } \\
\text { humanos }\end{array}$ & $\begin{array}{l}\text { El gobierno de Trinidad y } \\
\text { Tobago debe liberar a todas } \\
\text { las personas migrantes y } \\
\text { solicitantes de asilo que se } \\
\text { encuentran en detención } \\
\text { migratoria simplemente por } \\
\text { ingresar al país de manera } \\
\text { irregular o que esperan que } \\
\text { se resuelvan sus solicitudes } \\
\text { de asilo y darles acceso } \\
\text { a la atención de salud } \\
\text { que requieran y a otros } \\
\text { servicios esenciales, sin } \\
\text { discriminación. }\end{array}$ \\
\hline
\end{tabular}




\begin{tabular}{|c|c|c|}
\hline Países & Situaciones & $\begin{array}{l}\text { Recomendaciones de } \\
\text { Amnistía Internacional }\end{array}$ \\
\hline $\begin{array}{l}\text { ESTADOS } \\
\text { UNIDOS }\end{array}$ & $\begin{array}{l}\text { El Servicio de Inmigración y Control } \\
\text { de Aduanas del Departamento de } \\
\text { Seguridad Nacional de Estados Unidos } \\
\text { refirió un primer caso confirmado } \\
\text { de COVID-19 en instalaciones de } \\
\text { detención migratoria. } \\
\text { Amnistía Internacional ha recibido } \\
\text { testimonios perturbadores de } \\
\text { personas detenidas sobre condiciones } \\
\text { peligrosas en centros de detención } \\
\text { migratoria del ICE, que ponen a } \\
\text { quienes tienen problemas médicos } \\
\text { preexistentes en mayor peligro de } \\
\text { contraer el COVID-19 y de morir como } \\
\text { consecuencia del virus. }\end{array}$ & $\begin{array}{l}\text { Amnistía Internacional } \\
\text { emitirá un informe } \\
\text { documentando como } \\
\text { oficiales del DHS y } \\
\text { los centros del ICE no } \\
\text { han adoptado medidas } \\
\text { adecuadas para garantizar } \\
\text { la salud pública (por } \\
\text { ejemplo, suministrando } \\
\text { jabón y gel desinfectante } \\
\text { a las personas } \\
\text { detenidas, facilitando } \\
\text { el distanciamiento } \\
\text { social según estándares } \\
\text { internacionales y brindando } \\
\text { servicios de salud } \\
\text { adecuados y receptivos a } \\
\text { quienes presenten síntomas } \\
\text { de COVID-19). }\end{array}$ \\
\hline
\end{tabular}

Fuente: Elaboración propia, Pinho (2020).

\section{Acceso a la información}

Según el derecho internacional de los derechos humanos, los gobiernos tienen la obligación de proteger el derecho a la libertad de expresión, incluido el derecho a buscar, recibir y difundir información de todo tipo, independientemente de las fronteras. Po lo tanto, los gobiernos son responsables de proporcionar la información necesaria para la protección y promoción de los derechos, incluido el derecho a la salud. Las restricciones permisibles a la libertad de expresión por razones de salud pública, mencionadas anteriormente, no pueden poner en peligro el derecho propiamente dicho. (Human Rights Watch, 2020) 
El Comité de Derechos Económicos, Sociales y Culturales considera como una "obligación de prioridad" proporcionar "educación y acceso a la información relativa a los principales problemas de salud en la comunidad, con inclusión de los métodos para prevenir y combatir esas enfermedades". Una respuesta al COVID-19 respetuosa con los derechos humanos debe garantizar la disponibilidad y la accesibilidad universal de información precisa y actualizada sobre el virus. (Human Rights Watch, 2020)

El acceso a la información pública también debe ser prioridad en este contexto de pandemia. Recomiendan a los funcionarios públicos garantizar la difusión de "información oportuna y transparente, técnicamente correcta y basada en evidencias". "El público tiene derecho a la información que puede afectar su salud" y la de sus allegados, establece la Organización Mundial de la Salud. La Organización Panamericana de la Salud, además, considera indispensable "proporcionar información epidemiológica para realizar una evaluación de riesgos a nivel nacional, regional y global". (Chirinos, 2020)

Naciones Unidas, la CIDH y la Organización para la Seguridad y la Cooperación en Europa manifiestan en una declaración conjunta que "los gobiernos de todo el mundo están obligados, en virtud de las normas de los derechos humanos, a proporcionar información fidedigna en formatos accesibles a todos". Advierten que "cualquier intento de penalizar la información relativa a la pandemia puede crear desconfianza en la información institucional, retrasar el acceso a información fiable y tener un efecto silenciador en la libertad de expresión". (Chirinos, 2020)

Así mismo, dichos organismos internacionales manifiestan que:

Los gobiernos deben hacer esfuerzos excepcionales para proteger el trabajo de los periodistas. El periodismo cumple una función crucial en un momento de emergencia de salud pública, en particular cuando tiene por objeto informar al público sobre información crítica y monitorear las acciones del gobierno. (Chirinos, 2020, s/p). 
También alertan sobre los riesgos que se presentan en las medidas de censura, porque las restricciones informativas "no solo violan el derecho de las personas a la libertad de expresión y acceso a la información", sino que limitan la capacidad de los ciudadanos de protegerse frente a la enfermedad. (Chirinos, 2020)

Al tomar medidas contra periodistas y trabajadores de la salud, algunos gobiernos no han cumplido con su obligación de proteger el derecho a la libertad de expresión. Esta situación limitó la comunicación efectiva sobre el inicio de la enfermedad y socavó la confianza en las acciones del gobierno y ponen en peligro la eficacia de la respuesta en materia de salud pública, menoscabando el derecho a acceder a información sobre la salud. (Amnistía Internacional, 2020). Bachelet, en otra intervención, informó que "Las autoridades nunca deberían sancionar a los profesionales de la medicina porque estos señalen las deficiencias de que adolece la respuesta a la crisis". (Chirinos, 2020).

Tabla $\mathbf{N}^{\circ} 2$ Comparativa de países con ejemplos de casos sobre situaciones de DDHH en relación a los Derechos del Acceso a la Información y la Libertad de Expresión.

\begin{tabular}{|c|c|}
\hline País & Situación \\
\hline China & $\begin{array}{l}\text { Inicialmente retuvo información básica sobre el coronavirus del } \\
\text { público. } \\
\text { Se detuvieron a personas por informar sobre la epidemia en las } \\
\text { redes sociales y a usuarios de Internet por "propagar rumores", } \\
\text { censuraron conversaciones en línea sobre la epidemia y } \\
\text { restringieron los informes de los medios de comunicación. } \\
\text { Caso: la policía detuvo a Li Wenliang, médico de un hospital } \\
\text { de Wuhan donde se estaba tratando a pacientes infectados, por } \\
\text { "difundir rumores" después de advertir acerca del nuevo virus } \\
\text { en una aplicación de chat en línea. El medico murió a principios } \\
\text { de febrero a causa del virus COVID-19. }\end{array}$ \\
\hline
\end{tabular}




\begin{tabular}{|c|l|}
\hline País & \multicolumn{1}{c|}{ Situación } \\
\hline Irán & $\begin{array}{l}\text { El brote surgió después de que las autoridades dañaran } \\
\text { severamente la confianza pública al reprimir brutalmente las } \\
\text { protestas antigubernamentales generalizadas. } \\
\text { La tasa inusualmente alta de casos reportados así como } \\
\text { la inconsistencia en las cifras anunciadas por funcionarios } \\
\text { y fuentes de medios nacionales, han aumentado las } \\
\text { preocupaciones de que los datos estén siendo deliberadamente } \\
\text { manipulados o de que se estén recopilando y analizando } \\
\text { inadecuadamente }\end{array}$ \\
\hline Tailandia & $\begin{array}{l}\text { Informantes en el sector de la salud pública y periodistas en } \\
\text { línea se han enfrentado a demandas, represalias y actos de } \\
\text { intimidación por parte de las autoridades. Denunciaron casos } \\
\text { de presunta corrupción relacionada con el acaparamiento y la } \\
\text { especulación de mascarillas quirúrgicas y otros suministros } \\
\text { Algunos miembros del personal médico fueron amenazados con } \\
\text { medidas disciplinarias, incluida la terminación de sus contratos } \\
\text { de trabajo y la revocación de sus licencias, por denunciar la } \\
\text { grave escasez de suministros esenciales en los hospitales de } \\
\text { todo el país. }\end{array}$ \\
\hline Rusia & $\begin{array}{l}\text { Caso: Arresto violento y la continuidad de la detención de } \\
\text { la doctora rusa Anastasia Vasilyeva, líder de un sindicato } \\
\text { de profesionales médicos que denunció debilidades en } \\
\text { la preparación del sistema de salud para luchar contra el } \\
\text { coronavirus, CoviD-19. }\end{array}$ \\
\hline
\end{tabular}

Fuente: Elaboración propia, Pinho (2020).

Otros países si priorizaron la comunicación abierta y la presentación de información transparente sobre el número de casos del COVID-19, a saber: 
Tabla $N^{\circ} 3$ Comparativa de países que priorizaron la comunicación abierta

\begin{tabular}{|c|c|}
\hline País & Medidas en pro de la Comunicación \\
\hline Taiwán & $\begin{array}{l}\text { Adoptó medidas inmediatas para combatir el virus, incluida la } \\
\text { rápida difusión de información fidedigna al público. } \\
\text { Los comunicados de prensa diarios de los funcionarios de salud } \\
\text { y los anuncios de servicio público apuntan a contrarrestar la } \\
\text { información errónea y han ayudado a calmar el pánico, restaurar } \\
\text { la confianza del público y alentar la asistencia de las personas } \\
\text { durante la crisis. }\end{array}$ \\
\hline Singapur & $\begin{array}{l}\text { Publicó y actualizó periódicamente estadísticas detalladas sobre } \\
\text { el número y la tasa de infecciones y recuperaciones }\end{array}$ \\
\hline $\begin{array}{l}\text { Corea del } \\
\text { Sur }\end{array}$ & $\begin{array}{l}\text { Publicó datos de salud y los funcionarios emitían dos } \\
\text { comunicados diarios para establecer la confianza del público y } \\
\text { promover la vigilancia ciudadana }\end{array}$ \\
\hline Italia & $\begin{array}{l}\text { El gobierno ha celebrado conferencias de prensa diarias para } \\
\text { compartir datos y ha implementado una agresiva campaña } \\
\text { pública sobre mejores prácticas para que las personas se } \\
\text { protejan a sí mismas y a otras de la propagación del virus. }\end{array}$ \\
\hline
\end{tabular}

Fuente: Elaboración propia, Pinho (2020).

Para Amnistía Internacional (2020), la tecnología puede y debe desempeñar importantes funciones durante esta pandemia del COVID-19, como difundir mensajes de salud pública y aumentar el acceso a los servicios de salud. Lamentablemente, el aumento de los poderes de vigilancia digital de los Estados (el acceso a los datos de localización de teléfonos móviles) amenaza la privacidad, la libertad de expresión y la libertad de asociación de tal forma que podría violar derechos y minimizar la confianza en las autoridades públicas, con el consiguiente menoscabo de la eficacia de las repuestas de salud pública. Tales medidas entrañan además un riesgo de discriminación que pueden perjudicar a comunidades ya marginadas.

En esta situación de pandemia, el derecho de los derechos humanos, sigue siendo aplicable. De hecho, el marco de los 
derechos humanos tiene por objeto garantizar el equilibrio de los distintos derechos para proteger a las personas y las sociedades. Por lo tanto, los Estados no pueden excusarse de desatender el derecho a la privacidad y la libertad de expresión con el pretexto de gestionar una crisis de salud pública. Al contrario, la protección de los derechos humanos también promueve la salud pública. Es indiscutible que los gobiernos deben garantizar que toda restricción de estos derechos se ajuste a salvaguardar los derechos humanos. (Amnistía Internacional, 2020)

\section{Derecho de Acceso al Agua y al Saneamiento}

Los derechos al agua y el saneamiento son parte del derecho a un nivel de vida adecuado. El Comité de Derechos Económicos, Sociales y Culturales de la ONU ha reafirmado que los derechos al agua y el saneamiento son un componente esencial del derecho a un nivel de vida adecuado y "relacionados integralmente, entre otros derechos del Pacto, con el derecho a la salud". (Human Rights Watch, 2020)

Como ha señalado la OMS, la provisión de agua potable, el saneamiento y las condiciones higiénicas son esenciales para proteger la salud durante el brote de COVID-19. La prevención de la transmisión de persona a persona del coronavirus puede respaldarse en la promoción de los derechos al agua y el saneamiento, y en el apoyo a la infraestructura y los técnicos de agua y aguas residuales para garantizar la aplicación de prácticas de agua, saneamiento e higiene de manera consistente y correcta en comunidades, hogares, escuelas, mercados e instalaciones sanitarias. (Human Rights Watch, 2020)

Miles de millones de personas en todo el mundo no tienen acceso a agua potable. La escasez de agua potable y saneamiento en el hogar, la escuela o en entornos de atención médica dificultará la adopción de medidas preventivas. En algunos casos, sin agua ni saneamiento adecuado, estos entornos en sí mismos pueden ser un lugar para la propagación de la enfermedad. (Human Rights Watch, 2020) 
La infraestructura de atención médica de Venezuela es tan débil que la recomendación más básica, el lavado de manos, es difícil incluso para los proveedores de atención médica, quienes trabajan en condiciones precarias. Los médicos y enfermeras venezolanos entrevistados por Human Rights Watch en los últimos meses dijeron que el jabón y los desinfectantes eran prácticamente inexistentes en sus clínicas y hospitales. A medida que la inflación ha aumentado y los salarios se han devaluado, se ha vuelto imposible para ellos traer sus propios suministros. Los hospitales públicos en Caracas sufren escasez habitual de agua. En hospitales remotos, la insuficiencia ha durado semanas e incluso meses. Se ha pedido que los pacientes y el personal traigan su propia agua para beber y, en algunas ocasiones para descargar los inodoros. (Human Rights Watch, 2020)

Diversos expertos de la ONU expresan que ante la propagación del COVID-19 "los gobiernos de todo el mundo deben proporcionar acceso continuo a suficiente agua a las poblaciones que viven en las condiciones más vulnerables". Enfatizan que "la lucha mundial contra la pandemia tiene pocas posibilidades de éxito si la higiene personal, la principal medida para prevenir el contagio, no está al alcance de los 2.200 millones de personas que no tienen acceso a servicios de agua potable". Advierten, además, que el "acceso limitado al agua las hace más propensas a infectarse”. (Chirinos, 2020)

\section{Planes de Emergencia que han aplicado los Estados con motivo del COVID-19}

A continuación para presentar este punto, se va a hacer una breve descripción de las medidas o planes de emergencia que han implementado algunos países de América Latina en la Tabla $\mathrm{N}^{\circ} 4$. 


\section{Tabla $\mathbf{N}^{\circ} \mathbf{4}$ Comparativa de Venezuela y Centro América con sus Planes de Emergencia ante el COVID-19}

\begin{tabular}{|c|c|}
\hline País & Plan de Emergencia \\
\hline Venezuela & $\begin{array}{l}\text {-Se decretó la Cuarentena social voluntaria, el Estado de Alarma y } \\
\text { el cierre de restaurantes y tiendas no alimentarias. (Algarra, 2020) } \\
\text {-Suspensión durante seis meses del pago de arrendamiento } \\
\text { de inmuebles de uso comercial y de aquellos utilizados como } \\
\text { vivienda principal y la prohibición de los desalojos forzosos. } \\
\text {-Inamovilidad laboral hasta el } 31 \text { de diciembre de este año. Se } \\
\text { activó un plan especial del pago de nóminas a través del sistema } \\
\text { patria por un lapso de seis meses; suspensión de pago moratorio } \\
\text { de intereses de crédito. Suspendió el pago de interés de pago } \\
\text { de capital a todos los créditos otorgados por los bancos, aunque } \\
\text { desde hace meses la banca no otorga créditos; } \\
\text {-Prohibió,, durante los próximos seis meses, el corte de servicios } \\
\text { de telecomunicaciones y de servicios públicos. (Natera, 2020). } \\
\text {-Ministerio de Finanzas y Sudeban dictaron normas para favorecer } \\
\text { a todos los sectores productivos; Se aprueba la suspensión de } \\
\text { pagos de capital e intereses de todos los créditos del país por un } \\
\text { lapso de } 6 \text { meses. } \\
\text {-Se aprobó la exoneración de tributos y pago de cualquier arancel } \\
\text { a la importación de materia prima, bienes de capital e insumos. } \\
\text {-Se coordinó con empresas de telecomunicaciones para mejorar, } \\
\text { ampliar y garantizar los servicios durante esta coyuntura y la } \\
\text { prohibición, en los próximos seis meses, del corte de servicios de } \\
\text { telecomunicaciones, televisión por cable, telefonía o cualquier } \\
\text { medio de comunicación familiar. (Viera, 2020) }\end{array}$ \\
\hline Costa Rica & $\begin{array}{l}\text {-Gobierno anunció excepciones a la restricción vehicular. Y } \\
\text { aumento de multas y sanciones por violación a la restricción } \\
\text { vehicular durante emergencia por COVID-19 } \\
\text {-Cierre temporal de establecimientos clasificados como sitios de } \\
\text { reunión pública. } \\
\text {-Imposición de multas para quien violente ordenes sanitarias de } \\
\text { aislamiento } \\
\text {-Gobierno anunció excepciones a la restricción vehicular. Y } \\
\text { aumento de multas y sanciones por violación a la restricción } \\
\text { vehicular durante emergencia por COVID-19 } \\
\text {-Cierre temporal de establecimientos clasificados como sitios de } \\
\text { reunión pública. }\end{array}$ \\
\hline
\end{tabular}




\begin{tabular}{|c|l|}
\hline \multicolumn{1}{|c|}{ País } & \multicolumn{1}{|c|}{ Plan de Emergencia } \\
\hline Costa Rica & $\begin{array}{l}\text {-Imposición de multas para quien violente ordenes sanitarias de } \\
\text { aislamiento } \\
\text {-Ley de Alivia Fiscal ante el COVID-19: Contiene una moratoria } \\
\text { sobre el Impuesto sobre el Valor Agregado, Impuesto Selectivo de } \\
\text { Consumo y aranceles, durante los meses de abril, mayo y junio. } \\
\text { Asimismo, contiene una dispensa del pago parcial del Impuesto } \\
\text { sobre las Utilidades para los meses de abril, mayo y junio, así } \\
\text { como una exoneración del Impuesto sobre el Valor Agregado para } \\
\text { alquileres comerciales. Conceden moratoria de cuatro meses en } \\
\text { pago de impuestos turísticos } \\
\text {-Reducción temporal de jornadas de trabajo y medidas laborales } \\
\text { en sector público para combatir el COVID-19: se dispondrá la } \\
\text { permanencia de un máximo de 20 \% de funcionarios en las } \\
\text { instituciones, así como una abstención en el aumento salarial } \\
\text { (Sayagués, 2020) }\end{array}$ \\
\hline Panamá & $\begin{array}{l}\text {-Ley general sobre medidas de emergencia para afrontar la } \\
\text { crisis sanitaria causada por la pandemia del COVID-19: con el } \\
\text { fin de adoptar temporalmente medidas de emergencia para } \\
\text { proteger la vida de las personas, bienes y el patrimonio nacional } \\
\text { ante el grave riesgo colectivo que representa la crisis sanitaria } \\
\text { ocasionada por la pandemia del COVID-19. } \\
\text {-Servicio Nacional de Migración extiende vigencia de permisos } \\
\text { de residencia de extranjeros ante la situación de emergencia } \\
\text { en Panamá y extienden la vigencia de los permisos de trabajos } \\
\text { emitidos a trabajadores extranjeros ante la situación de } \\
\text { emergencia en Panamá por el COVID-19. } \\
\text {-Gobierno adopta medidas tributarias para aliviar el impacto } \\
\text { económico producto del Estado de Emergencia Nacional, concede } \\
\text { un plazo para el pago de tributos que se causen o deban pagarse } \\
\text { durante dicho periodo sin que ello conlleve el pago de intereses, } \\
\text { recargos y multas y extiende prórroga para la presentación y pago } \\
\text { de tributos } \\
\text {-Ministerio de Salud adopta medidas de movilidad ciudadana para } \\
\text { mitigar la propagación de la pandemia de COVID-19 e implementa } \\
\text { el Toque de Oueda. } \\
\text {-Aprobó Ley con medidas sociales especiales que suspenden } \\
\text { temporalmente el pago de servicios públicos en atención al } \\
\text { estado de emergencia nacional }\end{array}$ \\
\hline
\end{tabular}




\begin{tabular}{|c|l|}
\hline País & \multicolumn{1}{|c|}{ Plan de Emergencia } \\
\hline Panamá & $\begin{array}{l}\text {-Autoridad Nacional de Aduanas estableció la implementación } \\
\text { de un procedimiento temporal para la importación de mercancía } \\
\text { bajo modalidad especial de envío de socorro (ayuda y asistencia } \\
\text { humanitaria). (Sayagués, 2020) }\end{array}$ \\
\hline -Guatemala emite Ley de Emergencia para Proteger a los \\
Guatemaltecos de los efectos causados por la Pandemia \\
Coronavirus COVID-19. Vigilará que no se produzca acaparamien- \\
to; el personal del Estado debe estar disponible al Ilamado \\
oficial con el objeto de permitir el correcto funcionamiento de \\
las instituciones, y en consecuencia los servicios públicos; de \\
igual forma se facilitará la contratación del personal técnico \\
y profesional; Se prohíbe el cobro de multas, moras, gastos \\
administrados o intereses, generados por atrasos en pago de \\
cuotas correspondientes a centros educativos o de universidades; \\
asimismo, los estudiantes no estarán sujetos a expulsión u otras \\
sanciones; \\
-También se menciona la espera de las obligaciones crediticias, \\
otorgando diferimientos de hasta 6 meses sin intereses \\
moratorios, también para las personas que suscribieron convenios \\
de pago \\
-Gobierno declara toque de queda y dicta medidas adicionales \\
que deben tomarse en cuenta durante el Estado de Calamidad \\
-Continuidad de servicios básicos y prohibición de corte de estos \\
servicios: Prohibir el corte de servicios de energía eléctrica, agua, \\
teléfono e internet, por pagos atrasados. \\
-Congreso conoce de iniciativa para apoyar personas y familias \\
que se vean afectadas económicamente por el COVID-19. \\
(Sayagués, 2020)
\end{tabular}




\begin{tabular}{|c|c|}
\hline País & Plan de Emergencia \\
\hline $\begin{array}{l}\text { República } \\
\text { Dominicana }\end{array}$ & $\begin{array}{l}\text {-Dirección General de Impuestos Internos establece medidas } \\
\text { complementarias en relación al virus COVID-19: Aplazamiento de } \\
\text { acuerdos de pago; Exención del pago de anticipos del Impuesto } \\
\text { sobre la Renta (ISR). } \\
\text {-Superintendencia de Electricidad emite instrucción sobre no sus- } \\
\text { pensión de suministro eléctrico por falta de pago. (Sayagués, 2020) }\end{array}$ \\
\hline El Salvador & $\begin{array}{l}\text {-Se decretan medidas extraordinarias de prevención y contención } \\
\text { para declarar el territorio nacional como zona sujeta a control } \\
\text { sanitario, a fin de contener la pandemia COVID-19: indica quienes } \\
\text { son las personas autorizadas para circular en el período de } \\
\text { cuarentena. } \\
\text {-Dirección General de Impuestos Internos comunica que } \\
\text { declaraciones e informes deberán presentarse en línea: Ios plazos } \\
\text { para la presentación de las declaraciones e informes tributarios } \\
\text { no han sido modificados, por lo que se mantienen los establecidos } \\
\text { en el calendario, Código Tributario y Leyes correspondientes. } \\
\text {-Otorga beneficios fiscales relacionados con la contribución } \\
\text { especial de turismo, el Impuesto sobre la Renta del ejercicio } \\
\text { impositivo 2019 y el Pago o Anticipo a Cuenta de Impuesto sobre } \\
\text { la Renta. } \\
\text {-Se decreta: Suspensión del pago de la cuota de energía eléctrica } \\
\text { por } 3 \text { meses; Suspensión del pago de la cuota de agua por } \\
3 \text { meses; Congelamiento del cobro de créditos hipotecarios, } \\
\text { personales, tarjetas de crédito; Suspensión por } 3 \text { meses del pago } \\
\text { de la cuota de teléfono, cable e internet; Suspensión por } 3 \text { meses } \\
\text { de las cuotas de arrendamiento de los inmuebles. } \\
\text {-Restringe temporalmente derechos constitucionales para atender } \\
\text { la Pandemia COVID-19: La restricción a la libertad de tránsito; } \\
\text { Respecto a la restricción al derecho de los habitantes a reunirse } \\
\text { pacíficamente y sin armas, podrán prohibirse las reuniones } \\
\text { de habitantes, salvo que las mismas tengan fines religiosos, } \\
\text { culturales, económicos o deportivos, autorizadas previamente por } \\
\text { dichas autoridades, pero se limita las aglomeraciones de más de } \\
50 \text { personas. } \\
\text {-No se restringe la libertad de expresión, la libertad de difusión } \\
\text { del pensamiento, el derecho de asociación, la inviolabilidad } \\
\text { de la correspondencia, ni la interferencia o intervención de las } \\
\text { telecomunicaciones, así como ningún otro derecho o libertad } \\
\text { fundamental no comprendido en el Decreto. (Sayagués, 2020) }\end{array}$ \\
\hline
\end{tabular}




\begin{tabular}{|c|c|}
\hline País & Plan de Emergencia \\
\hline Honduras & $\begin{array}{l}\text {-Gobierno anuncia medidas adicionales para afrontar el } \\
\text { COVID-19: emite el decreto de Toque de Queda; Segmentación } \\
\text { de la población conforme a la terminación de los dígitos de su } \\
\text { tarjeta de identidad, pasaporte y/o carnet de residentes, para } \\
\text { que puedan abastecerse de alimentos, medicinas, combustibles } \\
\text { y realizar trámites; Queda prohibida la circulación de vehículos y } \\
\text { salida de personas a nivel nacional; Está prohibida la apertura de } \\
\text { restaurantes, establecimientos de comida rápida, cafés y otros } \\
\text { similares dedicados a la venta de alimentos, incluyendo el servicio } \\
\text { de entrega a domicilio; Durante la vigencia del toque de queda } \\
\text { los supermercados, farmacias y gasolineras están autorizados a } \\
\text { operar únicamente y sin excepción los días indicados; Se autoriza } \\
\text { la circulación del transporte pesado de alimentos, combustible, } \\
\text { insumos médicos, productos de exportación e importación, } \\
\text { agroexportadores y otros necesarios para atender la emergencia } \\
\text { nacional, siempre que cumplan con las medidas de bioseguridad } \\
\text { recomendadas. } \\
\text {-Secretaría de Trabajo y Seguridad Social anuncia medidas para } \\
\text { garantizar el mantenimiento de los empleos y la sostenibilidad } \\
\text { productiva de las empresas: Autorizar a los trabajadores y } \\
\text { empleadores del sector privado para que de común acuerdo } \\
\text { convengan que los días feriados que señala el Código de } \\
\text { Trabajo se consideren como otorgados y gozados por parte de } \\
\text { los trabajadores durante el período de vigencia del Estado de } \\
\text { Emergencia Sanitaria Nacional por la propagación del CoviD19. } \\
\text { Los empleadores podrán conceder a cuenta de vacaciones, los } \\
\text { días que en virtud del Estado de Emergencia los trabajadores no } \\
\text { se presenten a trabajar en su jornada ordinaria. Se exceptúa de } \\
\text { lo anterior, la obligatoriedad del patrono de poner en conocimien- } \\
\text { to al trabajador, con diez días de anticipación el goce de sus } \\
\text { vacaciones } \\
\text {-En materia tributaria: El Servicio de Administración de Rentas } \\
\text { comunica que se continuarán atendiendo consultas y brindando } \\
\text { asesoría a través del Contact Center: se amplían los plazos } \\
\text { para presentación de ciertas declaraciones y de fecha límite de } \\
\text { emisión de documentos fiscales; (Sayagués, 2020) }\end{array}$ \\
\hline
\end{tabular}

Fuente: Elaboración propia, Pinho (2020). 


\section{México y Nicaragua sin implementar medidas}

Frente a la tendencia general de clausurar fronteras y decretar encierros obligatorios para frenar la expansión del coronavirus, solo dos países en América Latina van a contracorriente de esta estrategia. (González, 2020).

El Gobierno Nicaragüense no ha dispuesto medidas especiales a la fecha, por lo que las obligaciones tributarias formales y materiales, las mantienen según lo dispuesto en sus normas internas; de igual forma, todo plazo se encuentra corriendo a la fecha. En ese sentido, el Gobierno hace un llamado a que las Compañías tomen las medidas necesarias con el fin de atender cualquier notificación o requerimiento de información por parte de las Autoridades, especialmente en aquellas donde se hayan dispuesto medidas de teletrabajo o similares. (Sayagués, 2020).

El gobierno Mexicano indicó que cada medida se implementará en su debido momento pero, ante las críticas, ya adelantó parte de la fase 2 de su plan de contingencia previsto para un escenario con cientos de contagios. Como consecuencia, todas las escuelas están cerradas y se dio inicio a una "jornada nacional de sana distancia" por un mes, en la que se recomienda a las empresas suspender actividades no esenciales o permitir que se hagan desde casa de manera remota, así como reprogramar eventos masivos. No fue sin embargo hasta el 19 de marzo de 2020 que el gobierno recomendó (no obligó) de manera pública a la población que se quedara en casa "si no es indispensable" salir. (González, 2020).

Para México, la fase 1 los casos son sólo de decenas, todos de importación o de contactos con esos afectados (ámbito familiar). La fase 2 ya es dispersión comunitaria, con contagios generados en la comunidad, pero todavía focalizados. La 3 es la epidémica, con miles de casos en todo el país. El subsecretario de Salud Hugo López Gatell, explicó, que a diferencia de otros países como China, Italia o Estados Unidos, que son de las economías más grandes, en México, aunque es la número 14 
en el mundo, la desigualdad hace imposible que las medidas de resguardo como la cuarentena o la restricción de movilidad se endurezcan. México llegará a la fase 3 de COVID-19, la epidémica, y lo hará en aproximadamente 15 días según información del subsecretario de Prevención y Promoción de la Salud.

\section{A manera de reflexión final}

Como se observó en las comparativas de los planes tomados por los países, muchos de ellos aprobaron leyes de emergencia y han tomado medidas que restringen la libertad de circulación, asociación, expresión y reunión pública, así como el derecho a la vida privada y familiar y el derecho a trabajar. Aunque algunas medidas de emergencia están justificadas, no los exime a cumplir que las medidas sean legales, necesarias y proporcionadas, que son temporales dada la situación y que están sujetas a una supervisión y revisión independientes; además no deben utilizarse como pretexto para negar la entrada a las personas refugiadas. Debe reconocerse el derecho a solicitar asilo, y no se debe devolver a las personas a lugares en los que pueda correr peligro de sufrir violaciones graves de derechos humanos, como actualmente está ocurriendo con muchos venezolanos que en estos momentos se encuentran pasando la frontera con Colombia para llegar a Venezuela motivado a que han sido expulsados de sus viviendas por no honrar el compromiso del pago del alquiler en virtud de las medidas de suspensión de los contratos de trabajo en el exterior.

Los Expertos de la ONU consideran que las restricciones a las libertades ciudadanas deben ser consideradas transitorias, y que deben ser aplicadas solo en el contexto de la pandemia. Cualquier respuesta de emergencia al coronavirus debe cumplir con los criterios establecidos: ser proporcionada, necesaria, no discriminatoria y no deben usarse como base para atacar a grupos particulares, minorías o individuos; además, no debe funcionar como una excusa para la acción represiva bajo pretexto de proteger la salud. 
La Oficina del Alto Comisionado de las Naciones Unidas emitió en su página web un comunicado oficial sobre el llamado a los Estados a no abusar o extralimitarse de las medidas de seguridad que impongan. Reconocen que el uso de los poderes en casos de emergencia es permitido por el derecho internacional en respuesta a amenazas significativas, pero se debe colocar los derechos humanos en el centro de la respuesta al brote del coronavirus.

Amnistía Internacional, por otro lado, ha publicado una serie de recomendaciones para los Estados de Europa en las que los insta a garantizar que sus respuestas a la COVID-19, sean conformes con sus obligaciones internacionales y regionales en materia de derechos humanos. Europe at a Crossroads establece unas directrices claras sobre lo que los gobiernos deben y no deben hacer en respuesta a la actual pandemia. Entre ellas se encuentra garantizar el derecho de las personas a la salud (para lo cual es necesario garantizar el derecho a la vivienda, el agua y el saneamiento) y garantizar la protección de los sectores más vulnerables de la sociedad. El acceso a la información es otro de los aspectos claves del derecho a la salud. Todas las personas tienen derecho a ser informadas de las medidas de respuesta adoptadas. No garantizar este derecho debilita la respuesta de los servicios de salud pública y pone en riesgo la salud de todo el mundo. No se sabe a ciencia cierta si Venezuela comunica cifras reales de la situación del COVID-19.

Lamentablemente en estos momentos, los grupos vulnerables (solicitantes de asilo, refugiadas y migrantes) que se encuentran en campos masificados, corren un mayor riesgo de contagiarse, por lo tanto urge que los Estados los protejan, incluso los que no tiene un hogar y los que están privados de libertad en prisiones, centros de detención para inmigrantes $u$ otro tipo de instituciones. El Papa Francisco en su oración "Urbi et Orbi", en la misa de Domingo de Resurrección (12 de abril de 2020) suplicó que se "reconforte el corazón de tantas personas refugiadas y desplazadas a causa de guerras, sequías y carestías. Que proteja a los numerosos migrantes y refugiados -muchos 
de ellos son niños-, que viven en condiciones insoportables, especialmente en Libia y en la frontera entre Grecia y Turquía" pidió además que sea eliminadas las sanciones internacionales que pesan sobre algunos países y también abogó por la condonación de las deudas. (Telesur, 2020)

En esta situación de crisis sanitaria, la cooperación internacional y la solidaridad son decisivas. Los gobiernos con capacidad económica y técnica para hacerlo, deben ayudar a los que tengan menos recursos para estar preparados para enfrentar los brotes. Igualmente, los Estados deben proporcionar a otros Estados y a las organizaciones internacionales información pertinente sobre el grado de propagación del COVID-19 en sus territorios, sus consecuencias, y la información de que dispongan sobre su posible tratamiento. Esta crisis coloca además de forma palpable, la interconexión entre la exclusión, la desigualdad y las violaciones de derechos humanos. Pero también brinda a los gobiernos la oportunidad de realizar los cambios radicales que se necesitan para ser una sociedad ideal, que respeta y coloca los derechos humanos sobre cualquier medida que se adopte.

\section{Bibliografía}

Algarra, Álvaro. (2020). Venezuela: aumentan medidas sanitarias en mercados por COVID-19. Voz de América. [Consulta Abril 8, 2020]. Recuperado de: https://www.voanoticias.com/a/ venezuela-aumentan-medidas-sanitarias-en-mercados-porcovid-19-/5351897.html

Amnistía Internacional. (2020). Américas: Los gobiernos deben poner fin a las detenciones peligrosas y discriminatorias de migrantes y solicitantes de asilo. [Consulta Abril 8, 2020]. Recuperado de: https://www.es.amnesty.org/en-que-estamos/noticias/noti cia/articulo/americas-los-gobiernos-deben-poner-fin-a-lasdetenciones-peligrosas-y-discriminatorias-de-migrantes/

Amnistía Internacional. (2020). AI presenta un decálogo de derechos bumanos para afrontar la pandemia del coronavirus. [Consulta Abril 7, 2020]. Recuperado de: https://www.es.amnesty. 
org/en-que-estamos/noticias/noticia/articulo/amnistia-internacional-presenta-un-decalogo-de-derechos-humanos-paraafrontar-la-pandemia/

Amnistía Internacional (2020). Rusia: Las autoridades detienen a la doctora que denunció deficiencias en la respuesta al coronavirus. [Consulta Abril 8, 2020]. Recuperado de: https://www. es.amnesty.org/en-que-estamos/noticias/noticia/articulo/ rusia-las-autoridades-detienen-a-la-doctora-que-denunciodeficiencias-en-la-respuesta-al-coronavirus/

Amnistía Internacional. (2020). Los Estados deben respetar los derechos humanos al emplear tecnologías de vigilancia digital para combatir la pandemia. [Consulta Abril 8, 2020]. Recuperado de: https://www.es.amnesty.org/en-que-estamos/noticias/noticia/ articulo/los-estados-deben-respetar-los-derechos-humanos-alemplear-tecnologias-de-vigilancia-digital-para-co/

Amnistía Internacional. (2020). Europa: Prioridades de derechos humanos para los Estados en su respuesta al coronavirus. [Consulta Abril 8, 2020]. Recuperado de: https://www. es.amnesty.org/en-que-estamos/noticias/noticia/articulo/ europa-prioridades-de-derechos-humanos-para-los-estadosen-su-respuesta-al-coronavirus/

Chirinos, Mariengracia. (2020). Derechos humanos para atender la pandemia de COVID-19. [Consulta Abril 7, 2020]. Recuperado de: https://prodavinci.com/derechos-humanos-para-atender-lapandemia-de-covid-19/

González Díaz, Marcos. (2020). Coronavirus: por qué México y Nicaragua son los países de América Latina con menos medidas restrictivas frente al covid-19. Corresponsal de $\mathrm{BBC}$ News Mundo en México y Centroamérica. [Consulta Abril 8, 2020]. Recuperado de: https://www.bbc.com/mundo/noticiasamerica-latina-52059566

Human Rights Watch.Org. (2020). Dimensiones de derechos humanos en la respuesta al COVID-19. Hora: 4:32 PM EDT. [Consulta Abril 7, 2020]. Recuperado de: https://www.hrw.org.

Natera Febres, David. (2020). Medidas económicas del gobierno para encarar emergencia del Covid-19 sobrecargan al sector privado. Correo del Caroní. [Consulta Abril 7, 2020]. Recuperado de: https://www.correodelcaroni.com/salud/ 
coronavirus/4795-maduro-confirmo-77-casos-de-coronavirusy-medidas-economicas-que-recaen-en-el-sector- \%E2 \%80 \% A6 Sayagués, Rafael. (2020). Medidas especiales de los gobiernos de Centroamérica respecto a COVID-19. EY Building a better working world. Actualizado a Abril 3, 2020. [Consulta Abril 7, 2020]. Recuperado de: https://www.ey.com/es_cr/tax/ medidas-especiales-covid-19

United Nations Human Rights. Office of the High Commissioner. (16, Marzo 2020). COVID-19: States should not abuse emergency measures to suppress human rights - UN experts. Ginebra. [Consulta Abril 7, 2020]. Recuperado de: https:// www.ohchr.org/EN/NewsEvents/Pages/DisplayNews. aspx?NewsID=25722\&LangID=E

Telesur, (2020). El Papa pide eliminación de sanciones y condonación de la deuda. TeleSUR - JGN, Noticias Mundo. [Consulta Abril 12, 2020]. Recuperado de: https://www. telesurtv.net/news/papa-francisco-mensaje-urbi-orbi-pascuapandemia-20200412-0006.html

Tomasino, Erick. (2020). El Salvador: Covid-19 y estado de excepción. [Consulta Abril 7, 2020]. Fuente: Rebelión. América Latina y Caribe. Recuperado de: https://rebelion.org/covid-19y-estado-de-excepcion/

Viera Rivas, Romer. (2020). Activado plan especial de pago de nóminas para pequeñas, medianas empresas y comercios. Edición Impresa: Correo del Orinoco, pagina 2. Número 3.739. [Consulta Abril 8, 2020]. Recuperado de: http://www.correodelorinoco. gob.ve/wp-content/uploads/2020/03/Edici\%C3\%B3n-ImpresaCorreo-del-Orinoco-N \%C2 \%B0-3739-Mi \%C3 \%A9rcoles25-de-Marzo-de-2020-1.pdf 